\title{
USING A GAS ION SOURCE FOR RADIOCARBON AMS AND GC-AMS
}

\author{
Christopher Bronk Ramsey ${ }^{1}$ Peter Ditchfield $•$ Martin Humm \\ Oxford Radiocarbon Accelerator Unit, University of Oxford, United Kingdom.
}

\begin{abstract}
This paper reports on the performance of a new method of sample injection using the High Voltage Engineering Europa (HVEE) SO-110 ion source jointly developed between HVEE and Oxford. In order to use this source, we have developed a new gas handling system which works on the direct injection of carbon dioxide mixed into a continuous flow of helium. Preliminary work has also been carried out on online gas chromatography-accelerator mass spectrometry (GC-AMS). In this application, a GC is directly coupled to the AMS system using a GC-IRMS combustion interface and Nafion ${ }^{\mathrm{TM}}$ drier. We show here results for the measurement of natural abundance in separated compounds with good peak separation and precisions of about $10 \%$. This type of system should be ideal for source apportionment studies, biomedical, and other similar work where high precision is not required but where sample sizes are very low.
\end{abstract}

\section{INTRODUCTION}

Gas ion sources lend themselves very well to the measurement of very small samples because it removes the necessity of graphitization and the consequent handling of the very small quantities of solid material. The existing gas handling systems developed at Oxford, however, were best suited to samples $>30 \mu \mathrm{g} \mathrm{C}$ because of dead volumes associated with the bellows arrangement originally used (Bronk Ramsey 1994a; Bronk Ramsey and Hedges 1997). The system was also complicated because of the need for a high vacuum system and automated liquid nitrogen trap at the target potential of the ion source (typically $>24 \mathrm{kV}$ ).

With the joint project to develop a gas ion source with High Voltage Engineering Europa (HVEE) following the joint work on the design of an ion source for biomedical AMS applications (Mous et al. 1998), it was decided to try to redesign the gas inlet system to be simpler, more mechanically robust, and to operate at ground potential. This is made possible by using GC-type technology and by introducing the gas into the ion source using a helium carrier gas.

Online GC works in a similar way. It had already been demonstrated that small pulses of gas could be measured in an ion source of this kind (Bronk Ramsey and Hedges 1994c). With the SO-110 ion source, we have now demonstrated that this works in practice using an Agilent ALS 6890A GC coupled through a PDZ Europa Orchid combustion/drier system direct to the AMS.

\section{GAS INJECTION SYSTEM}

The gas injection system is shown schematically in Figure 1 . The system is essentially a 2-stage concentrator and can be used either with online combustion with GC purification (as discussed in Bronk Ramsey and Humm 2000, provided here by a Carlo Erba NA1500 nitrogen/carbon analyzer) or an ampoule cracker system (Bronk Ramsey and Hedges 1994b, 1997). The dilute carbon dioxide from these systems is transferred to the AMS injection system (into the line marked "In" in Figure 1) and trapped into trap 1, while the previous sample is being injected into the AMS system from trap 2. When the analysis for the previous sample has finished, the second trap is flushed with helium and then the gas transferred from trap 1 to trap 2 (as shown in Figure 2). The second trap has a much lower internal diameter and is attached to a capillary with an overall length of about $3 \mathrm{~m}$. This is sufficient to hold about $80 \mu \mathrm{g} \mathrm{C}$ in the form of pure $\mathrm{CO}_{2}$, so after the trap is warmed the smaller capillary holds a plug of fairly pure $\mathrm{CO}_{2}$, which is then slowly injected into the source over a period of up to $25-30 \mathrm{~min}$. To control the flow into the source, a closed-split dilution (controlled

\footnotetext{
${ }^{1}$ Corresponding author. Email: christopher.ramsey@archaeology-research.oxford.ac.uk.

(C) 2004 by the Arizona Board of Regents on behalf of the University of Arizona

Proceedings of the 18th International Radiocarbon Conference, edited by N Beavan Athfield and R J Sparks

RADIOCARBON, Vol 46, Nr 1, 2004, p 25-32
} 


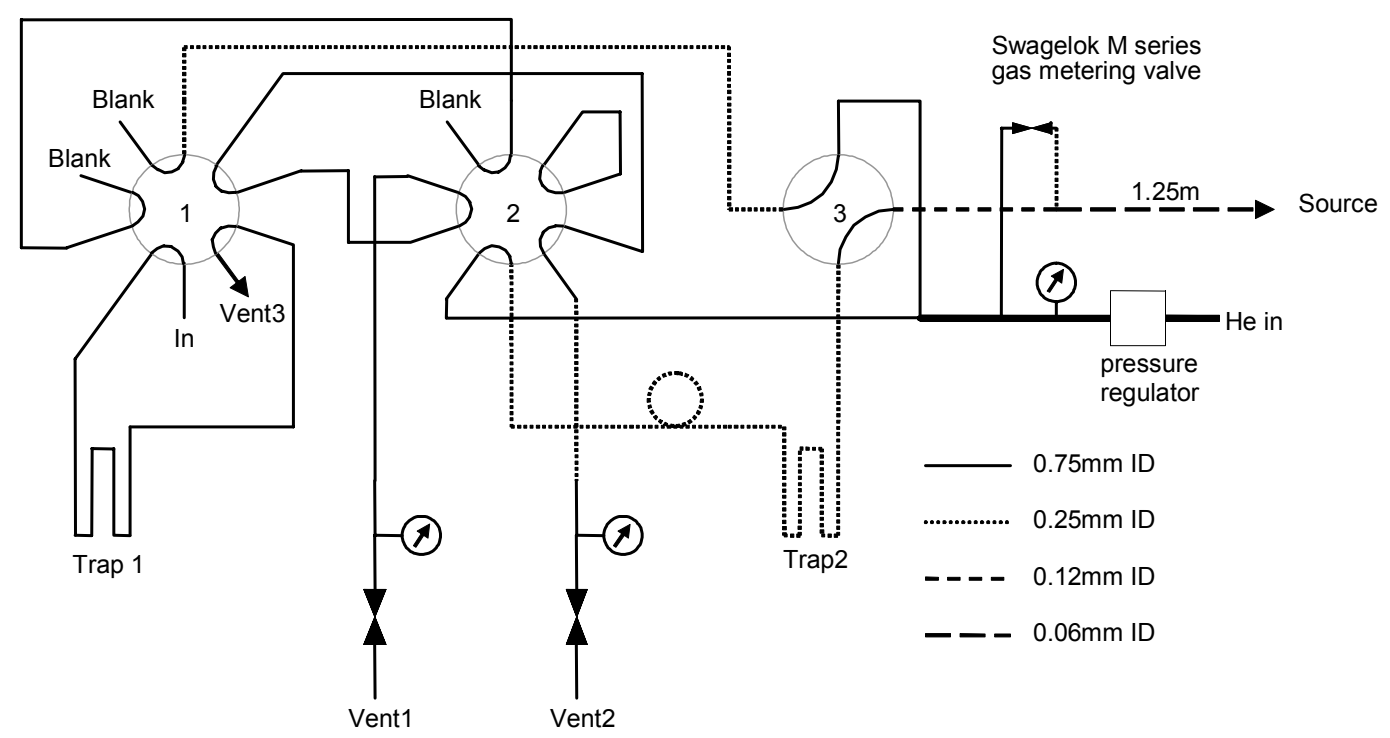

Figure 1 Schematic of the new gas handling system for the gas ion source at Oxford. The main elements of the system are 3 VICI 2-position multi-port valves (labelled 1,2, and 3 in the diagram) and 2 automatic liquid nitrogen traps. The liquid nitrogen traps are mechanically manipulated Statebourne Bio2 long-term storage vessels which are capable of holding liquid nitrogen for about a week in this installation. See main text for description of operation. The valves in this figure are shown in the configuration for collection of $\mathrm{CO}_{2}$ in trap 1 and injection into the AMS from trap 2.

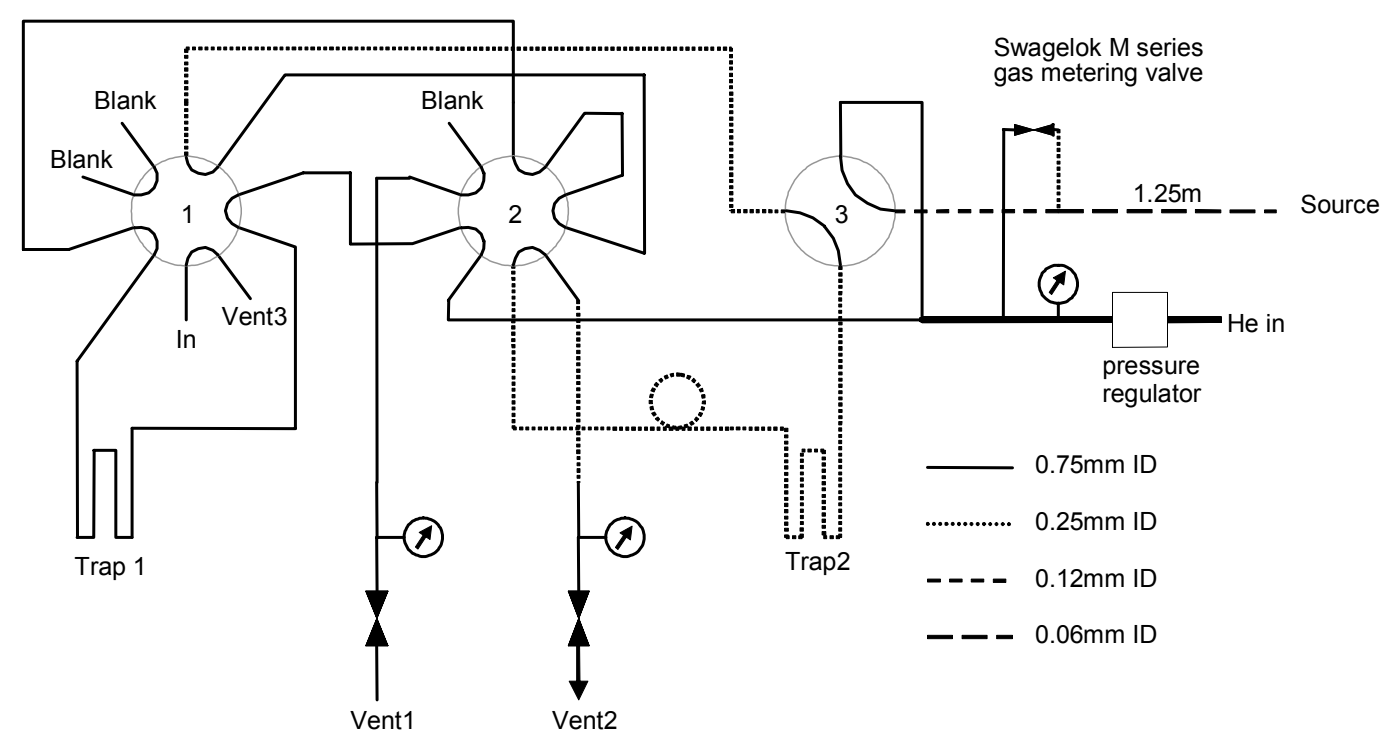

Figure 2 Gas handling system with the valves in the configuration for transfer of gas from trap 1 to trap 2. Here the mode of operation of valves 1,2 , and 3 can be seen: the central plug in the valve rotates to achieve a different selection of connections.

by the Swagelok M series gas dosing valve shown in Figure 1) is used with a He flow rate of about $0.5 \mathrm{~mL} / \mathrm{min}$. This flow of carrier gas keeps the capillary into the source flushed the whole time. For very small samples, this dilution can be switched off or reduced. 
There are 3 main reasons for using a 2-stage concentrator rather than a single-stage:

- In order to obtain a fairly constant flow of $\mathrm{CO}_{2}$ from this kind of system, the $\mathrm{CO}_{2}$ needs to be concentrated to close to $100 \%$; this is only possible with a low capillary diameter $(0.25 \mathrm{~mm})$. The output flows from online combustion systems and our ampoule rig are too high to trap $\mathrm{CO}_{2}$ in such a fine capillary.

- The fine capillary used for injection into the AMS can only take a limited amount of $\mathrm{CO}_{2}$, and so a first stage concentration and expansion allows excess gas to be vented before trapping it into the AMS injection loop.

- Finally, there is an advantage, particularly when using online combustion, to perform the combustion and collection while the previous sample is being injected into the AMS. This increases the proportion of time spent making measurements by a factor of nearly 2 .

Single-stage concentrators (such as that devised by Uhl et al. 2004) have the advantage of simplicity and may, therefore, be better for samples at the low end of the mass scale $(<10 \mu \mathrm{g} \mathrm{C})$.

The whole system operates under positive pressure and the input pressure into the source is about 2 bar. The material for the capillaries is found to be important in minimizing cross-contamination effects. Peak and other polymer-based capillaries do increase such effects, and so the system is now almost entirely stainless steel with a methyl deactivated silica capillary into the ion source. A typical application using this gas injection system (run during tests of the system on the old AMS at Oxford) is published in Staddon et al. (2003).

\section{OPERATION OF THE GAS ION SOURCE FOR ROUTINE $\mathrm{CO}_{2}$ DATING}

In routine operation, the gas injection system is used to automatically inject a predefined sequence of samples. The whole gas system (gas injection assembly, $\mathrm{CHN}$ analyzer, and ampoule manifold) are controlled using NuDAM ${ }^{\mathrm{TM}}$ modules on an RS-485 network. The software used for handling the gas transfers is integrated with the HVEE AMS software via the Windows messaging system. Batches of samples can be run while the system is unattended, which is important given the relatively long collection times.

The operating parameters and characteristics of the SO-110 ion source are shown in Table 1. The maximum currents are typically several times lower than those for graphite; thus, it makes sense to use the system either when only low precision is required or when the samples are sufficiently small that there are real advantages in not having to graphitize. Overall detection efficiency is about double what we had on the original General Ionex AMS system. The typical current profile is shown in Figure 3. The duty cycle is typically about $16 \mathrm{~min}$ data collection and $4 \mathrm{~min}$ between samples, flushing the source, changing the target, and preparing the next gas. The collected data from a series of samples is shown in Figure 4. This shows a slight cross-contamination (typically $0.5 \%$ ) from sample to sample. In normal operation, two or more backgrounds are run immediately after the HOXII standards in order to estimate this value for the particular run and the analysis software automatically corrects for the effect. In practice, this has very little impact on precision as the correction can be accurately corrected for.

The data analysis software, developed for analysis of the gas run data, first subtracts the average yields for all 3 isotopes that are measured prior to gas injection. The cross-contamination time constant and scale are then estimated and corrected current profiles calculated; the integrated charge for all 3 isotopes is then found. From that point on, the data can be handled in exactly the same way as for graphite sample and undergoes the same tests for reproducibility of standards and known-age 


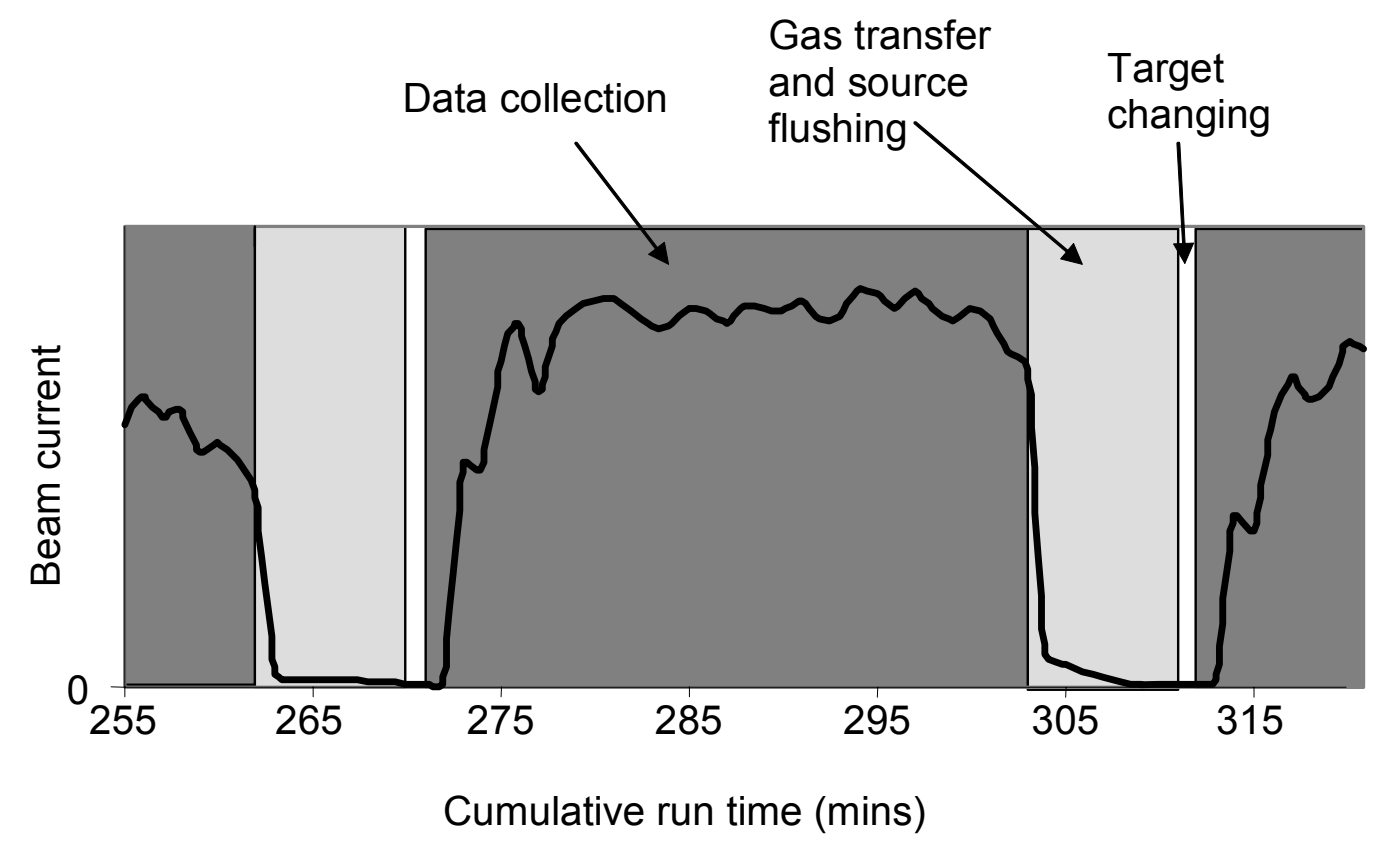

Figure 3 Current profile during a routine gas run (for typical maximum values, see Table 1 or Figure 4). While the data is being collected on one sample, the next one is being prepared. There is then a short period of about $3-4$ min during which the new sample is transferred to the injection capillary and the ion source is flushed with pure Helium. A new target is then inserted into the source and the next sample injected at a fairly constant rate. The concentration and re-dilution ensures a fairly well controlled and constant gas flow, which is better suited to the source's performance than a fast pulse if the sample size is larger than a few $\mu \mathrm{g}$.

samples. Because the gas handling, injection, and ion source all produce some mass-dependent fractionation, the ${ }^{13} \mathrm{C} /{ }^{12} \mathrm{C}$ ratio is not as stable as it usually is for graphite samples, and between samples can vary by as much as $0.5 \%$ (within sample variation is typically higher than this). However, this does not seem to affect the accuracy of the final radiocarbon date measurements which can still be better than $0.5 \%$ (as we observe on a finer scale for graphite; see Bronk Ramsey et al. 2004).

\section{GC-AMS}

In order to use the AMS for online GC AMS, we used an Agilent ALS 6890A GC coupled through a PDZ Europa Orchid combustion/drier system. This system is designed for GC-IRMS and comprises a GC separation system, the outlet of which can be directed either to a Flame Ionization Detector (FID) or an online combustion system. The combustion system is made up of a combustion column containing platinum and oxidized copper wires followed by a Nafion ${ }^{\mathrm{TM}}$ drier. In the case of GC-AMS, because we wish to measure the $\mathrm{CO}_{2}$ in real-time from the GC, we injected the output of the online combustion system directly into the AMS through an open split.

In our application, the flow rate is set to $2 \mathrm{~mL} / \mathrm{min}$ with a $1 \mathrm{~mL} / \mathrm{min}$ makeup flow into the combustion system. In order to test the system, we have made up a solution in hexane of $0.5 \%$ of 3 compounds: hexadecane (petrochemical origin), methyl palmitate (made from palm oil), and methyl oleate (made 


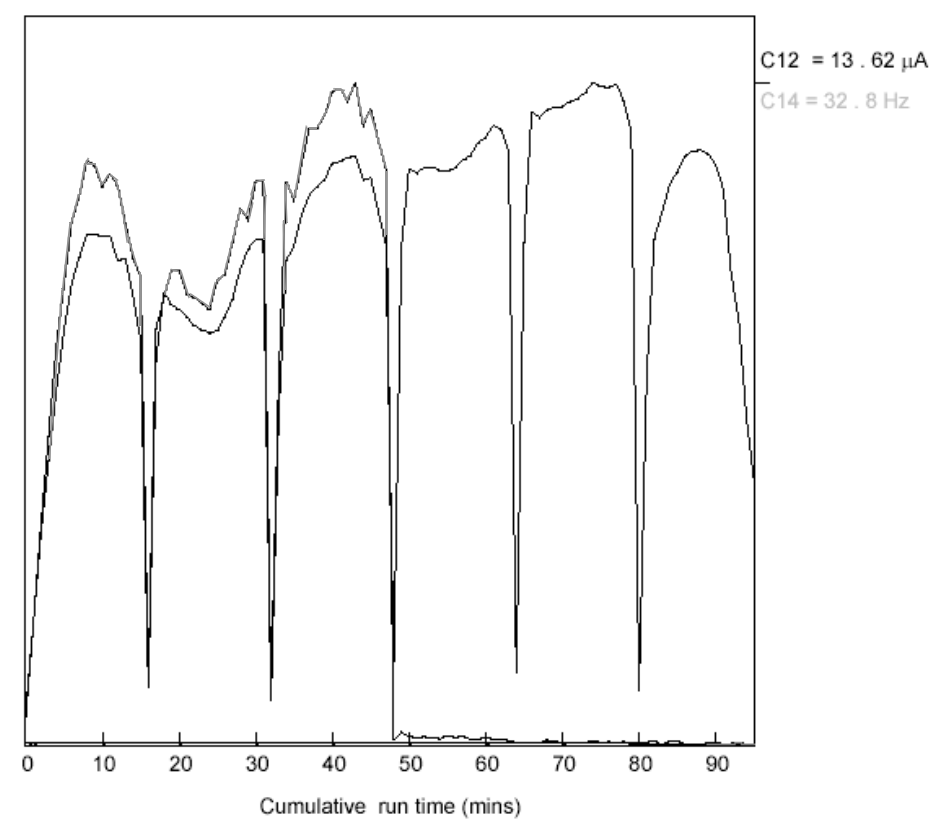

Figure 4 Data collected for a series of 3 HOXII standards followed by 3 background samples which should contain no ${ }^{14} \mathrm{C}$. Cross-contamination is visible in the first background after the OXII-this is about $0.5 \%$ of the value of the previous sample and is corrected for by the analysis software. The currents shown are ${ }^{12} \mathrm{C}^{3+}$ (chopper corrected) and ${ }^{14} \mathrm{C}$ count rate.

Table 1 Operational parameters and performance of the SO-110 gas ion source. Currents given are maximal during the gas injection cycle. The source has emittance limiting apertures which are estimated to reduce the beam by $50-70 \%$ and so we can only estimate the true maximum beam from the source and its efficiency. For some applications where precision is not an issue, these apertures could probably be removed.

\begin{tabular}{ll}
\hline Parameter & Typical values \\
\hline Target voltage & $8.5 \mathrm{kV}$ \\
Extraction voltage & $26.7 \mathrm{kV}$ \\
Ionizer current & $15.0 \mathrm{~A}$ \\
Caesium reservoir & $97 \mathrm{C}$ \\
${ }^{12} \mathrm{C}^{-}$from source (before apertures) & $15-20 \mathrm{uA}$ (estimated) \\
Source efficiency & $3-4 \%$ (estimated) \\
\hline
\end{tabular}

from olive oil). We expect the first to contain no ${ }^{14} \mathrm{C}$ and the other 2 to have modern concentrations. One $\mu \mathrm{L}$ of the solution was injected and the GC programmed to follow a temperature cycle:

- $60 \mathrm{~s}$ at $150^{\circ} \mathrm{C}$;

- $10^{\circ} \mathrm{C}$ per min ramp to $163^{\circ} \mathrm{C}$ (over $78 \mathrm{~s}$ );

- $60 \mathrm{~s}$ at $163^{\circ} \mathrm{C}$;

- $30^{\circ} \mathrm{C}$ per min ramp to $300{ }^{\circ} \mathrm{C}$ (over $274 \mathrm{~s}$ );

- $900 \mathrm{~s}$ at $300^{\circ} \mathrm{C}$. 
The GC column was a HP-5 (Crosslinked 5\% PH ME Soloxane, $30 \mathrm{~m} \times 0.32 \mathrm{~mm} \times 0.25 \mu \mathrm{m}$ film thickness, HP Part nr 19091J-413). The FID can be used to test the GC separation and identify the peaks. For GC-AMS, the flow is switched over to the combustion system/AMS after the solvent peak has come through. The injection to the source is an open split with a $500 \mathrm{~mm} \times 0.075 \mathrm{~mm}$ (ID) methyl deactivated silica capillary (SGE prod code: 0624450) into the source, which gives rise to a flow rate of about $0.5 \mathrm{~mL} / \mathrm{min} \mathrm{He}$. The split ratio is, therefore, about 1:5 (source:waste). For higher sensitivity, the flow rate through the GC could be lowered, but this would compromise GC performance. Figure 5 shows a GC-AMS trace with the separated compounds. All 3 isotopes of carbon are measured (the stable isotopes using CMTE 7803 digitizers, and the ${ }^{14} \mathrm{C}$ using the AMS detector) in 1-s blocks.

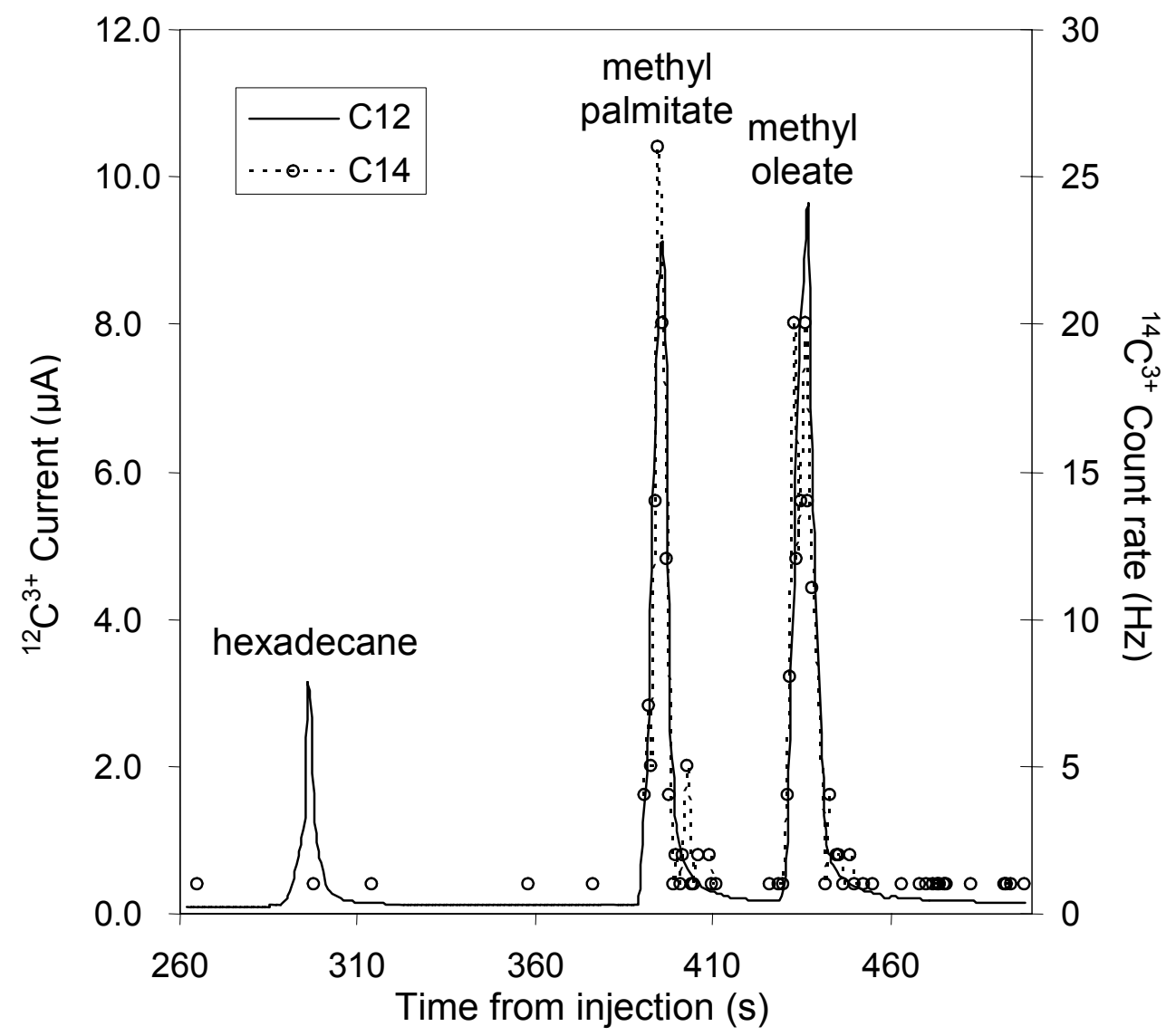

Figure 5 Example of direct GC-AMS using the SO-110 ion source. The 3 compounds injected have been easily separated and the correct isotope ratios for each compound determined (see main text for details).

The peak widths are fairly good with FWHM about $4 \mathrm{~s}$ on the AMS, compared to $2 \mathrm{~s}$ on the FID, showing that good separations can be obtained. There is some low-level tailing present (easiest to see on the ${ }^{14} \mathrm{C}$ counts on the right of Figure 5). For closely spaced peaks, some form of de-convolution would be useful. The only aspect of the trace which is not yet properly understood is the response characteristic. The hexadecane peak on the FID is broader and lower but should be similar in area-so there seems to be some non-linearity. 
Using a 15-s window on the individual peaks (and normalizing to the absolute ratio for HOXII we get on routine gas runs), we obtain the following ${ }^{14} \mathrm{C}$ concentrations for the peaks:

- Hexadecane: $0.036 \pm 0.036 \mathrm{fM}$;

- Methyl palmitate: $1.055 \pm 0.103 \mathrm{fM}$;

- Methyl oleate: $1.076 \pm 0.101 \mathrm{fM}$.

These values are, within the quoted errors, what we would expect for these samples. The stable isotope ratios are all within a range of $\pm 0.5 \%$, which, likewise, is as we would expect. In this case, with just under $1 \mu \mathrm{g} \mathrm{C}$ per peak being injected into the source, we are getting precision on modern material of about $10 \%$. Backgrounds would appear to be of the order of $3 \%$ or $30 \mu \mathrm{g} \mathrm{C}$ in the injection system, though may be non-linear.

\section{CONCLUSIONS}

The HVEE SO-110 source coupled with the gas injection system, described here, allows routine measurements on gas samples down to a few $\mu \mathrm{g}$ (Staddon et al. 2003). The whole system is completely automated and the gas injection system is substantially simpler than previous versions (Bronk Ramsey and Hedges 1994b), which should make it more reliable. The main technical advantage is that the whole sample is now flushed into the ion source instead of using a bellows system (with associated dead volumes). Mechanically, the system is simpler because there are no vacuum pumps, no bellows mechanism, and the assembly is at ground potential. Overall detection efficiency is higher by a factor of about 2 than the previous system at Oxford (in part because of the improved AMS transmission); other aspects of the performance are similar on normal-sized samples ( $>30 \mu \mathrm{g} \mathrm{C})$.

We have shown that the ion source can also be used for online GC-AMS with very fast time response (additional FWHM about $2 \mathrm{~s}$ ) and with precisions of about $10 \%$ for injected masses of less than $1 \mu \mathrm{g} \mathrm{C}$ of modern material. Absolute isotope ratios (stable isotope and ${ }^{14} \mathrm{C}$ ) are in accordance with expectations. We expect this to be a valuable method for compound specific work where only low precision is required (e.g. source apportionment and biomedical work).

\section{ACKNOWLEDGEMENTS}

Funding through NERC; members of ORAU staff for building the gas handling system and helping with the GC interface; Jen Tripp, who provided invaluable advice on the GC aspects of the work; the staff of HVEE (Dirk Mous, Andreas Gottdang, Matthias Klein, and Rein van den Broek) for supporting this work and for all of the work on the new ion source for which this system has been developed; also particular thanks to Hans van Bergen (HVEE) who did so much of the installation of the new AMS system and SO-110 ion source.

\section{REFERENCES}

Bronk Ramsey C, Hedges REM. 1994a. Carbon dioxide sputter source development at Oxford. Nuclear Instruments and Methods in Physics Research B 92:100-4.

Bronk Ramsey C, Hedges REM. 1994b. Gas handling systems for radiocarbon dating by AMS. Nuclear Instruments and Methods in Physics Research B 92: 105-10.

Bronk Ramsey C, Hedges REM. 1994c. Radiocarbon with gas chromatography. Radiocarbon 37(2):711-6.

Bronk Ramsey C, Hedges REM. 1997. Hybrid ion sources: radiocarbon measurements from microgram to milligram. Nuclear Instruments and Methods in Physics Research B 123:539-45.

Bronk Ramsey C, Humm MJ. 2000. On-line combustion of samples for AMS and ion source developments at ORAU. Nuclear Instruments and Methods in Physical Research B 172:242-6.

Bronk Ramsey C, Higham TFG, Leach P. 2004. Towards high precision AMS: progress and limitations. Radiocarbon, these proceedings.

Mous DJW, Fokker W, van den Broek R, Koopmans R, Bronk Ramsey C, Hedges REM. 1998. An ion source 
for the $\mathrm{HVEE}{ }^{14} \mathrm{C}$ isotope ratio mass spectrometer for biomedical applications. Radiocarbon 40(1):283-8.

Staddon PL, Bronk Ramsey C, Ostle N, Ineson P, Fitter A. 2003. Rapid turnover of hyphae of mycorrhizal fungi determined by AMS microanalysis of ${ }^{14} \mathrm{C}$.
Science 300:1138-40.

Uhl T, Kretschmer W, Luppold W, Scharf A. 2004. Direct coupling of an elemental analyser and a hybrid ion source for AMS measurements. Radiocarbon, these proceedings. 